\title{
Chronic pain diagnoses and opioid dispensings among insured individuals with serious mental illness
}

\author{
Ashli Owen-Smith ${ }^{1,2^{*}}$, Christine Stewart ${ }^{3}$, Musu M. Sesay ${ }^{2}$, Sheryl M. Strasser ${ }^{1}$, Bobbi Jo Yarborough ${ }^{4}$, \\ Brian Ahmedani ${ }^{5,6}$, Lisa R. Miller-Matero ${ }^{5,6}$, Stephen C. Waring ${ }^{7}$, Irina V. Haller ${ }^{7}$, Beth E. Waitzfelder ${ }^{8}$, \\ Stacy A. Sterling ${ }^{9}$, Cynthia I. Campbell ${ }^{10}$, Rulin C. Hechter ${ }^{10}$, John E. Zeber ${ }^{11}$, Laurel A. Copeland ${ }^{12}$, \\ Jeffrey F. Scherrer ${ }^{13}$, Rebecca Rossom ${ }^{14}$ and Greg Simon ${ }^{3}$
}

\begin{abstract}
Background: Individuals with major depressive disorder (MDD) and bipolar disorder (BD) have particularly high rates of chronic non-cancer pain (CNCP) and are also more likely to receive prescription opioids for their pain. However, there have been no known studies published to date that have examined opioid treatment patterns among individuals with schizophrenia.
\end{abstract}

Methods: Using electronic medical record data across 13 Mental Health Research Network sites, individuals with diagnoses of MDD $(N=65,750), B D(N=38,117)$ or schizophrenia or schizoaffective disorder $(N=12,916)$ were identified and matched on age, sex and Medicare status to controls with no documented mental illness. CNCP diagnoses and prescription opioid medication dispensings were extracted for the matched samples. Multivariate analyses were conducted to evaluate (1) the odds of receiving a pain-related diagnosis and (2) the odds of receiving opioids, by separate mental illness diagnosis category compared with matched controls, controlling for age, sex, Medicare status, race/ethnicity, income, medical comorbidities, healthcare utilization and chronic pain diagnoses.

Results: Multivariable models indicated that having a MDD $(\mathrm{OR}=1.90 ; 95 \% \mathrm{Cl}=1.85-1.95)$ or $\mathrm{BD}(\mathrm{OR}=1.71 ; 95 \%$ $\mathrm{Cl}=1.66-1.77)$ diagnosis was associated with increased odds of a CNCP diagnosis after controlling for age, sex, race, income, medical comorbidities and healthcare utilization. By contrast, having a schizophrenia diagnosis was associated with decreased odds of receiving a chronic pain diagnosis $(\mathrm{OR}=0.86 ; 95 \% \mathrm{Cl}=0.82-0.90)$. Having a MDD $(\mathrm{OR}=2.59 ; 95 \% \mathrm{Cl}=2.44-2.75)$ or $\mathrm{BD}(\mathrm{OR}=2.12 ; 95 \% \mathrm{Cl}=1.97-2.28)$ diagnosis was associated with increased odds of receiving chronic opioid medications, even after controlling for age, sex, race, income, medical comorbidities, healthcare utilization and chronic pain diagnosis; having a schizophrenia diagnosis was not associated with receiving chronic opioid medications.

Conclusions: Individuals with serious mental illness, who are most at risk for developing opioid-related problems, continue to be prescribed opioids more often than their peers without mental illness. Mental health clinicians may be particularly well-suited to lead pain assessment and management efforts for these patients. Future research is needed to evaluate the effectiveness of involving mental health clinicians in these efforts.

Keywords: Chronic non-cancer pain, Opioids, Serious mental illness

\footnotetext{
* Correspondence: aowensmith@gsu.edu

${ }^{1}$ Health Policy and Behavioral Sciences, School of Public Health, Georgia

State University, Urban Life Building, 140 Decatur Street, Suite 434, Atlanta,

GA 30303, USA

${ }^{2}$ Center for Research and Evaluation, Kaiser Permanente Georgia, Atlanta,

USA

Full list of author information is available at the end of the article
}

(c) The Author(s). 2020 Open Access This article is distributed under the terms of the Creative Commons Attribution 4.0 International License (http://creativecommons.org/licenses/by/4.0/), which permits unrestricted use, distribution, and reproduction in any medium, provided you give appropriate credit to the original author(s) and the source, provide a link to the Creative Commons license, and indicate if changes were made. The Creative Commons Public Domain Dedication waiver (http://creativecommons.org/publicdomain/zero/1.0/) applies to the data made available in this article, unless otherwise stated. 


\section{Background}

Chronic non-cancer pain (CNCP) affects an estimated 25.3 million Americans [1] at a cost of $\$ 600$ billion [2]. The use of long-term opioid therapy as a treatment for $\mathrm{CNCP}$ has quadrupled in the last 15 years [3-5] despite little empirical evidence that opioids are effective for treating $\mathrm{CNCP}$ long-term [6,7] and has instead resulted in dramatic increases in opioid abuse and overdose deaths $[8,9]$. In order to more effectively address this epidemic, we need to better understand which populations are most burdened by CNCP and which populations are at the greatest risk of opioid use/abuse in order to guide both clinical and policy-related decisions.

Evidence suggests that individuals with mental illness may be one population with particularly high rates of $\mathrm{CNCP}$ and may also be more likely to receive prescription opioids for their pain. Several studies have reported that individuals with depression and bipolar disorder, for example, have more frequent pain complaints, higher pain intensity and more pain chronicity and are also significantly more likely to receive long-term opioids, at a higher daily dose, and with greater days supplied compared with patients without mental illness [10-16]. By contrast, evidence suggests that $\mathrm{CNCP}$ is less prevalent among individuals with schizophrenia compared to individuals without mental illness [17]; to our knowledge, there have been no studies published to date that have examined opioid treatment patterns specifically among individuals with schizophrenia compared to controls.

This gap in the literature, in addition to other methodological limitations inherent in many prior studies including small sample sizes $[13,18]$ and limited generalizability (e.g., examining only military veterans) $[11,15,19]$ - prompted the present study. Specifically, we investigated (1) whether individuals with major depressive disorder (MDD), bipolar disorder (BD) and schizophrenia are more or less likely to receive a chronic pain diagnosis compared to individuals with no psychiatric diagnoses and (2) whether individuals with MDD, $\mathrm{BD}$ and schizophrenia are more or less likely to receive chronic prescription opioid medications compared to individuals with no psychiatric diagnoses using data from health care systems in the Mental Health Research Network (MHRN) that are representative of a large, geographically and racially/ethnically diverse population across the U.S.

\section{Methods}

\section{Data source}

The MHRN consists of 13 research centers located within large integrated health care delivery systems, serving over 12.5 million individuals across 15 states; most of these delivery systems also have affiliated health insurance plans. All MHRN sites maintain a Virtual Data
Warehouse consisting of electronic health record (EHR) and insurance claim data for all enrolled members or patients. Data on encounters, pharmacy fills, diagnoses, laboratory tests and demographics are organized using standardized definitions across sites and are quality checked locally [20].

The current study involved 10 MHRN systems. These sites were 6 Kaiser Permanente sites (Georgia, Washington, Northwest, Hawaii, Northern California, Southern California), Henry Ford Health System, Essentia Health, Baylor Scott and White Healthcare and Health Partners. Institutional Review Boards at each site approved the study protocol for this project.

\section{Study population}

Individuals were included if they met the following criteria: adults aged 18-70 years (as of January 1, 2016) with a diagnosis of MDD (ICD-9296.2-296.39/ICD-10 F32-F33.9), BD (ICD-9296.0x, 296.1x, 29.40-296.89/ ICD-10 F30-F31.9) or schizophrenia including schizoaffective disorder (ICD-9295.x/ICD-10 F20.x, F25.x) documented at least two times by mental healthcare provider in 2015 or 2016 (cases had to "start" 2016, the 12-month study period, with a diagnosis so at least 1 diagnosis had to occur in 2015). Patients who had diagnoses in more than 1 of these categories were categorized hierarchically: schizophrenia $>$ BD $>$ MDD. For example a patient with schizophrenia and MDD would be classified in the schizophrenia group and a patient with only MDD would be classified in the MDD group. This is an approach used in prior studies that have similarly employed a hierarchy of non-overlapping categories [21, 22]. Eligible individuals had to have continuous health plan membership throughout 2015 and 2016 (but could have a gap in enrollment records of $\leq 30$ days, as administrative gaps can occur as a result of delays in membership data processing and thus are not indicative of membership interruptions/disenrollment). Individuals with any cancer or metastatic cancer diagnoses (ICD9140-165, 170-172, 174-176, 179-199, 200-208, 238.6/ ICD-10 C00-26.9, C30.x, C37-C41.9, C43.x, C45-C45.7, C45.9, C46-C58, C60-C76.8, C7A.x, C7B,x, C80.x, C81C85.99, C86.x, C88.x, C90-C96.9, D03.x, D45, D47.Z9,) during this same time period were excluded.

Controls were identified using the same criteria as described above except that they had no documented mental illness diagnoses during 2015 or 2016 (they could not "start" 2016, the 12-month study period, with a diagnosis nor receive one during 2016). Matching was done separately for each group (e.g., schizophrenia controls were selected and removed from the pool of controls, then BD controls, followed by MDD controls). Controls for each group were matched on age (in 4-year bands), sex and Medicare status using stratified random sampling. 
Matching cases to controls was 1:2 for schizophrenia diagnosis and 1:1 each for BP and MDD diagnoses. These ratios were based on what numbers were required to find an adequate number of controls for each group.

\section{Measures}

Non-cancer chronic pain diagnoses documented on at least 2 dates in 2016 were extracted for the matched samples. The chronic pain conditions extracted included: back pain, neck pain, limb/extremity pain, arthritis, fibromyalgia/widespread muscle pain, headache, orofacial/ear/temporomandibular pain, abdominal/bowel pain, chest pain, urogenital/pelvic/menstrual pain, fractures/contusions/sprains/strains and other painful conditions [which included sickle cell disease, complex regional pain syndrome, systemic lupus erythematosus, acquired deformities (excluding spinal disorders), spinal cord injury and neuropathic pain]. The list of ICD codes used for identifying pain conditions are available online (https://github.com/MHResearchNetwork/MHRN-Central/ blob/master/WP_MHRN_SMI_painOpioids.zip).

Prescription opioid medication dispensings were also extracted for the matched samples. We were specifically interested in chronic opioid use, defined by prescriptions dispensed that covered at least 70 days in any 90-day period or $6+$ dispensings in 2016. This definition was based on prior studies conducted at one of the MHRN sites [23, 24]. The list of NDC codes used for identifying opioid medication dispensings are also available online (https://github.com/MHResearchNetwork/MHRN-Central/ blob/master/WP_MHRN_SMI_painOpioids.zip).

We also examined sociodemographic (age, sex, race/ ethnicity, neighborhood socioeconomic status) and clinical characteristics of the study population using data from 2016 using methods similar to prior work [25]. Overall medical comorbidity burden was calculated using the Charlson Comorbidity Index Score (CCIS). This score consists of 19 categories of comorbidity, with each category weighted based on the adjusted risk of 1year post-discharge mortality. The overall comorbidity score reflects the cumulative increased likelihood of mortality 1 year after discharge such that higher scores are indicative of a more severe burden of comorbidity [26]. Total health care utilization (hospitalizations, ED visits and other in-person outpatient encounters) was based on summarized data from the last 6 months of 2015. This timeframe was selected so that we had a baseline measure of recent utilization history prior to the study period (which was 2016). Multiple encounters occurring on the same day were coded as a single encounter so that we were able to count utilization days. In order to investigate whether any site variation existed and ensure the accuracy of the data before aggregation, preliminary data comparisons across sites were conducted. This comparison found very little site variation, supporting the stability of the aggregated estimates.

\section{Analyses}

The primary goals of our analyses were to examine whether having a diagnosis of MDD, BD or schizophrenia/schizoaffective disorder was associated with receipt of a chronic pain diagnosis and then subsequent chronic opioid prescription dispenses. For initial bivariate models, we used t-tests for continuous variables and Pearson $x^{2}$-tests for categorical data. Multivariate analyses were conducted to evaluate (1) the odds of receiving a chronic pain-related diagnosis and (2) the odds of receiving opioids, by separate mental illness diagnosis category compared with matched controls, controlling for age, sex, Medicare status, race/ethnicity, income, medical comorbidities, healthcare utilization and chronic pain diagnoses. Results of the models were reported as adjusted odds ratios (ORs) with $95 \%$ confidence intervals (CIs).

\section{Results}

The total number of patients identified was 377,927 (248, 283 cases, 129,644 controls); however, only one-third of the available MDD cases were included in the final dataset (selected randomly) because there were not a sufficient number of controls available. The sample of persons with MDD and matched controls (total $n=131,488$ ) included $72 \%$ women, $86 \%$ with a neighborhood income $>\$ 40,000$ per year, was $57 \%$ White, 9\% Black/African-American, $22 \%$ Hispanic/Latino, and between the ages of 18 and 70 (mean: 43.5, SD: 13.8). Individuals with MDD were more likely to have higher Charlson comorbidity scores and greater healthcare utilization than matched controls without psychiatric illness; they were also more likely to have any CNCP diagnosis $(62.4 \%$ compared to $39.8 \%$ of controls) and to receive chronic opioid medications (10.1\% compared to $2.4 \%$ of controls; see Table 1 ).

The sample of persons with BP and matched controls (total $n=76,232$ ) included $67 \%$ women, $85 \%$ with a neighborhood income $>\$ 40,000$ per year, was $60 \%$ White, 9\% Black/African-American, 18\% Hispanic/Latino, and between the ages of 18 and 70 (mean: 42.7, SD: 13.3). Individuals with $\mathrm{BP}$ were similarly more likely to have a higher Charlson comorbidity score and a greater healthcare utilization than matched controls without any psychiatric illness; they were also more likely to have any CNCP diagnosis (61.5\% compared to $40.3 \%$ of controls) and receive chronic opioid medications (10.4\% compared to $3.0 \%$ of controls; see Table 2).

The sample of persons with schizophrenia and matched controls (total $n=38,707$ ) included $44 \%$ women, $83 \%$ with a neighborhood income $>\$ 40,000$ per year, was $51 \%$ 
Table 1 Patients with Major Depressive Disorder (MDD) compared to Matched Controls

\begin{tabular}{|c|c|c|c|c|}
\hline Characteristic & $\begin{array}{l}\text { Patients with MDD } \\
(N=65,750) \\
n(\%) / \text { Mean } \pm S D\end{array}$ & $\begin{array}{l}\text { Matched Controls } \\
(\mathrm{N}=65,738) \\
\mathrm{n}(\%) / \text { Mean } \pm \mathrm{SD}\end{array}$ & Test Statistic & $p$-value \\
\hline Total & 65,750 & 65,738 & & \\
\hline Age & $43.5 \pm 13.8$ & $43.5 \pm 13.8$ & $t=-0.14$ & 0.89 \\
\hline \multicolumn{5}{|l|}{ Sex } \\
\hline Male & $18,733(28.5 \%)$ & $18,731(28.5 \%)$ & \multirow[t]{2}{*}{$x^{2}=0$} & \multirow[t]{2}{*}{0.99} \\
\hline Female & $47,013(71.5 \%)$ & $47,005(71.5 \%)$ & & \\
\hline Medicare & $6329(9.6 \%)$ & $6322(9.6 \%)$ & $x^{2}=0$ & 0.96 \\
\hline \multicolumn{5}{|l|}{ Race } \\
\hline White/Caucasian & $43,647(66.3 \%)$ & $31,328(47.7 \%)$ & \multirow[t]{7}{*}{$x^{2}=5891.77$} & \multirow[t]{7}{*}{$<0.0001$} \\
\hline Black/African-American & $5894(9.0 \%)$ & $5940(9.0 \%)$ & & \\
\hline Asian & $3850(5.9 \%)$ & $8846(13.5 \%)$ & & \\
\hline Pacific Islander & $540(0.8 \%)$ & $791(1.2 \%)$ & & \\
\hline Native American & $672(1.0 \%)$ & $462(0.7 \%)$ & & \\
\hline Other & $180(0.3 \%)$ & $165(0.3 \%)$ & & \\
\hline Unknown & $10,944(16.6 \%)$ & 18,199 (27.7\%) & & \\
\hline Ethnicity (Hispanic) & $14,134(21.5 \%)$ & $15,274(23.2 \%)$ & $x^{2}=57.19$ & $<0.0001$ \\
\hline \multicolumn{5}{|l|}{ Neighborhood Income } \\
\hline$<\$ 40,000$ per year & $7771(11.8 \%)$ & $7648(11.6 \%)$ & \multirow[t]{2}{*}{$x^{2}=0.12$} & \multirow[t]{2}{*}{0.73} \\
\hline$>\$ 40,000$ per year & $56,796(86.4 \%)$ & $55,566(84.5 \%)$ & & \\
\hline Charlson Comorbidity Index & $0.56+1.19$ & $0.25+0.74$ & $t=56.17$ & $<0.0001$ \\
\hline Total healthcare utilization in last 6 mos & $8.3 \pm 10.7$ & $2.3 \pm 4.3$ & $t=132.57$ & $<0.0001$ \\
\hline \multicolumn{5}{|l|}{ Pain conditions } \\
\hline Any Pain & $41,036(62.4 \%)$ & $26,158(39.8 \%)$ & $x^{2}=6731.57$ & $<0.0001$ \\
\hline Back pain & $13,419(20.4 \%)$ & $5944(9.0 \%)$ & $x^{2}=3382.42$ & $<0.0001$ \\
\hline Neck pain & $6877(10.5 \%)$ & $3031(4.6 \%)$ & $x^{2}=1613.80$ & $<0.0001$ \\
\hline Limb/extremity pain, arthritis & $21,239(32.3 \%)$ & $12,449(18.9 \%)$ & $x^{2}=3081.38$ & $<0.0001$ \\
\hline Fibromyalgia/widespread muscle & $4262(6.5 \%)$ & $976(1.5 \%)$ & $x^{2}=2146.34$ & $<0.0001$ \\
\hline Headache & $8359(12.7 \%)$ & $6261(4.8 \%)$ & $x^{2}=2580.33$ & $<0.0001$ \\
\hline Orofacial/ear/temporomandibular & $728(1.1 \%)$ & $409(0.6 \%)$ & $x^{2}=90.22$ & $<0.0001$ \\
\hline Abdominal/bowel pain & $9922(15.1 \%)$ & $4679(7.1 \%)$ & $x^{2}=2116.78$ & $<0.0001$ \\
\hline Chest pain & $4995(7.6 \%)$ & $2417(3.7 \%)$ & $x^{2}=949.73$ & $<0.0001$ \\
\hline Urogenital/pelvic/menstrual pain & $3222(4.9 \%)$ & $1638(2.5 \%)$ & $x^{2}=535.78$ & $<0.0001$ \\
\hline Fractures/contusions/sprains/strains & $8542(13.0 \%)$ & $4405(6.7 \%)$ & $x^{2}=1465.45$ & $<0.0001$ \\
\hline Other painful conditions ${ }^{a}$ & $7994(12.2 \%)$ & $3253(5.0 \%)$ & $x^{2}=2184.48$ & $<0.0001$ \\
\hline Chronic opioid use $\mathrm{b}^{\mathrm{b}}$ & $6618(10.1 \%)$ & $1553(2.4 \%)$ & $x^{2}=3346.72$ & $<0.0001$ \\
\hline
\end{tabular}

Includes sickle cell disease, complex regional pain syndrome, systemic lupus erythematosus, acquired deformities (excluding spinal disorders), spinal cord injury, lyme disease, neuropathic pain

${ }^{\mathrm{b}}$ Chronic use defined by $70+$ days supply in a 90-day period, receiving $6+$ dispenses in a year

White, 13\% Black/African-American, 22\% Hispanic/Latino, and between the ages of 18 and 70 (mean: 42.3, SD: 13.8). Individuals with schizophrenia had lower neighborhoodlevel incomes, higher Charlson comorbidity scores, and greater healthcare utilization than matched controls without any psychiatric illness; they were also slightly more likely to have any $\mathrm{CNCP}$ diagnosis $(47.2 \%$ compared to
$42.0 \%$ of controls) and receive chronic opioid medications (6.5\% compared to $5.0 \%$ of controls; see Table 3 ).

Multivariable models indicated that having a MDD $(\mathrm{OR}=1.90 ; 95 \% \mathrm{CI}=1.85-1.95)$ or $\mathrm{BD}(\mathrm{OR}=1.71 ; 95 \%$ $\mathrm{CI}=1.66-1.77)$ diagnosis was associated with increased odds of receiving a comorbid chronic pain diagnosis after controlling for age, sex, race, income, medical 
Table 2 Patients with Bipolar Disorder compared to Matched Controls

\begin{tabular}{|c|c|c|c|c|}
\hline Characteristic & $\begin{array}{l}\text { Patients with Bipolar Disorder } \\
(N=38,117) \\
\mathrm{n}(\%) / \text { Mean } \pm \mathrm{SD}\end{array}$ & $\begin{array}{l}\text { Matched Controls } \\
(N=38,115) \\
\mathrm{n}(\%) / \text { Mean } \pm \mathrm{SD}\end{array}$ & Test Statistic & $p$-value \\
\hline Age & $42.7 \pm 13.2$ & $42.7 \pm 13.3$ & $t=-0.20$ & 0.84 \\
\hline \multicolumn{5}{|l|}{ Sex } \\
\hline Male & $12,530(32.9 \%)$ & $12,530(32.9 \%)$ & \multirow[t]{2}{*}{$x^{2}=0$} & \multirow[t]{2}{*}{0.99} \\
\hline Female & $25,585(67.1 \%)$ & $25,583(67.1 \%)$ & & \\
\hline Medicare & $6386(16.8 \%)$ & $6383(16.8 \%)$ & $x^{2}=0$ & 0.98 \\
\hline \multicolumn{5}{|l|}{ Race } \\
\hline White/Caucasian & $27,348(71.8 \%)$ & $18,408(48.3 \%)$ & \multirow[t]{7}{*}{$x^{2}=5450.33$} & \multirow[t]{7}{*}{$<0.0001$} \\
\hline Black/African-American & 3410 (9.0\%) & 3594 (9.4\%) & & \\
\hline Asian & $1782(4.7 \%)$ & $4993(13.1 \%)$ & & \\
\hline Pacific Islander & $281(0.7 \%)$ & $453(1.2 \%)$ & & \\
\hline Native American & $499(1.3 \%)$ & $281(0.7 \%)$ & & \\
\hline Other & $94(0.3 \%)$ & $117(0.3 \%)$ & & \\
\hline Unknown & $4694(12.3 \%)$ & $10,262(27.0 \%)$ & & \\
\hline Ethnicity (Hispanic) & $5473(14.4 \%)$ & $8307(21.8 \%)$ & $x^{2}=711.63$ & $<0.0001$ \\
\hline \multicolumn{5}{|l|}{ Neighborhood Income } \\
\hline$<\$ 40,000$ per year & $4985(13.1 \%)$ & $4835(12.7 \%)$ & \multirow[t]{2}{*}{$x^{2}=0.41$} & \multirow[t]{2}{*}{0.52} \\
\hline$>\$ 40,000$ per year & $32,544(85.4 \%)$ & $32,006(84.0 \%)$ & & \\
\hline Charlson Comorbidity Index & $0.55 \pm 1.10$ & $0.28+0.81$ & $t=39.21$ & $<0.0001$ \\
\hline Total healthcare utilization in last 6 mo & $8.6 \pm 11.3$ & $2.4 \pm 4.8$ & $t=99.04$ & $<0.0001$ \\
\hline \multicolumn{5}{|l|}{ Pain conditions } \\
\hline Any Pain & $23,423(61.5 \%)$ & $15,342(40.3 \%)$ & $x^{2}=3426.65$ & $<0.0001$ \\
\hline Back pain & $7756(20.4 \%)$ & $3650(9.6 \%)$ & $x^{2}=1737.92$ & $<0.0001$ \\
\hline Neck pain & $3713(9.7 \%)$ & $1805(4.7 \%)$ & $x^{2}=711.12$ & $<0.0001$ \\
\hline Limb/extremity pain, arthritis & $12,052(31.6 \%)$ & $7401(19.4 \%)$ & $x^{2}=1492.66$ & $<0.0001$ \\
\hline Fibromyalgia/widespread muscle & $2384(6.3 \%)$ & $663(1.7 \%)$ & $x^{2}=1012.43$ & $<0.0001$ \\
\hline Headache & $5000(13.1 \%)$ & $1845(4.8 \%)$ & $x^{2}=1597.48$ & $<0.0001$ \\
\hline Orofacial/ear/temporomandibular & $477(1.3 \%)$ & $237(0.6 \%)$ & $x^{2}=81.42$ & $<0.0001$ \\
\hline Abdominal/bowel pain & $5777(15.2 \%)$ & $2821(7.4 \%)$ & $x^{2}=1145.30$ & $<0.0001$ \\
\hline Chest pain & 3009 (7.9\%) & $1348(3.5 \%)$ & $x^{2}=671.51$ & $<0.0001$ \\
\hline Urogenital/pelvic/menstrual pain & $1925(5.1 \%)$ & $959(2.5 \%)$ & $x^{2}=336.23$ & $<0.0001$ \\
\hline Fractures/contusions/sprains/strains & $5567(14.6 \%)$ & $2743(7.2 \%)$ & $x^{2}=1076.93$ & $<0.0001$ \\
\hline Other painful conditions ${ }^{a}$ & $4137(10.9 \%)$ & $2034(5.3 \%)$ & $x^{2}=779.68$ & $<0.0001$ \\
\hline Chronic opioid use $\mathrm{b}^{\mathrm{b}}$ & $3961(10.4 \%)$ & $1156(3.0 \%)$ & $x^{2}=1648.10$ & $<0.0001$ \\
\hline
\end{tabular}

Includes sickle cell disease, complex regional pain syndrome, systemic lupus erythematosus, acquired deformities (excluding spinal disorders), spinal cord injury, lyme disease, neuropathic pain

${ }^{\mathrm{b}}$ Chronic use defined by $70+$ days supply in a 90-day period, receiving $6+$ dispenses in a year

comorbidities and healthcare utilization. By contrast, having a schizophrenia diagnosis $(\mathrm{OR}=0.86 ; 95 \% \mathrm{CI}=$ $0.82-0.90)$ was associated with decreased odds of receiving a chronic pain diagnosis (see Table 4).

Having a MDD $(\mathrm{OR}=2.59 ; 95 \% \mathrm{CI}=2.44-2.75)$ or $\mathrm{BD}$ $(\mathrm{OR}=2.12 ; 95 \% \mathrm{CI}=1.97-2.28)$ diagnosis was associated with increased odds of receiving chronic opioid medications, even after controlling for age, sex, race, income, medical comorbidities, healthcare utilization and having a chronic pain diagnosis; having a schizophrenia diagnosis was not associated with receiving chronic opioid medications (see Table 4).

\section{Discussion}

The present study found that individuals with MDD and $\mathrm{BD}$ diagnoses were significantly more likely to receive 
Table 3 Patients with Schizophrenia compared to Matched Controls

\begin{tabular}{|c|c|c|c|c|}
\hline Characteristic & $\begin{array}{l}\text { Patients with Schizophrenia } \\
(N=12,916) \\
n(\%) / \text { Mean } \pm S D\end{array}$ & $\begin{array}{l}\text { Matched Controls } \\
(N=25,791) \\
\mathrm{n}(\%) / \text { Mean } \pm \mathrm{SD}\end{array}$ & Test Statistic & $p$-value \\
\hline Age & $42.3 \pm 13.8$ & $42.3 \pm 13.9$ & $t=0.34$ & 0.73 \\
\hline \multicolumn{5}{|l|}{ Sex } \\
\hline Male & $7250(56.1 \%)$ & $14,459(56.1 \%)$ & \multirow[t]{2}{*}{$x^{2}=0.02$} & \multirow[t]{2}{*}{0.90} \\
\hline Female & $5666(43.9 \%)$ & $11,332(43.9 \%)$ & & \\
\hline Medicare & $5144(39.8 \%)$ & $10,247(39.7 \%)$ & $x^{2}=0.03$ & 0.86 \\
\hline \multicolumn{5}{|l|}{ Race } \\
\hline White/Caucasian & $6889(53.3 \%)$ & $12,770(49.5 \%)$ & \multirow[t]{7}{*}{$x^{2}=1021.25$} & \multirow[t]{7}{*}{$<0.0001$} \\
\hline Black/African-American & $2476(19.2 \%)$ & $2724(10.6 \%)$ & & \\
\hline Asian & $1317(10.2 \%)$ & $3008(11.7 \%)$ & & \\
\hline Pacific Islander & $153(1.2 \%)$ & $343(1.3 \%)$ & & \\
\hline Native American & $138(1.1 \%)$ & $204(0.8 \%)$ & & \\
\hline Other & $28(0.2 \%)$ & $44(0.2 \%)$ & & \\
\hline Unknown & $1907(14.8 \%)$ & $6696(26.0 \%)$ & & \\
\hline Ethnicity (Hispanic) & $2511(19.4 \%)$ & $6045(23.4 \%)$ & $x^{2}=79.87$ & $<0.0001$ \\
\hline \multicolumn{5}{|l|}{ Neighborhood Income } \\
\hline$<\$ 40,000$ per year & $2404(18.6 \%)$ & $3444(13.4 \%)$ & \multirow[t]{2}{*}{$x^{2}=170.42$} & \multirow[t]{2}{*}{$<0.0001$} \\
\hline$>\$ 40,000$ per year & $10,345(80.1 \%)$ & 21,650 (83.9\%) & & \\
\hline Charlson Comorbidity Index & $0.63 \pm 1.18$ & $0.43+1.07$ & $t=-16.58$ & $<0.0001$ \\
\hline Total healthcare utilization in last 6 mo & $7.9 \pm 10.9$ & $2.6 \pm 5.6$ & $t=-63.60$ & $<0.0001$ \\
\hline \multicolumn{5}{|l|}{ Pain conditions } \\
\hline Any Pain & $6092(47.2 \%)$ & $10,835(42.0 \%)$ & $x^{2}=92.96$ & $<0.0001$ \\
\hline Back pain & $1855(14.4 \%)$ & $2687(10.4 \%)$ & $x^{2}=129.23$ & $<0.0001$ \\
\hline Neck pain & $754(5.8 \%)$ & $1228(4.8 \%)$ & $x^{2}=20.52$ & $<0.0001$ \\
\hline Limb/extremity pain, arthritis & $2942(22.8 \%)$ & $5312(20.6 \%)$ & $x^{2}=24.41$ & $<0.0001$ \\
\hline Fibromyalgia/widespread muscle & $386(3.0 \%)$ & $463(1.8 \%)$ & $x^{2}=57.13$ & $<0.0001$ \\
\hline Headache & $973(7.5 \%)$ & $1264(4.9 \%)$ & $x^{2}=109.52$ & $<0.0001$ \\
\hline Orofacial/ear/temporomandibular & $112(0.9 \%)$ & $150(0.6 \%)$ & $x^{2}=10.44$ & 0.0012 \\
\hline Abdominal/bowel pain & $1497(11.6 \%)$ & $1907(7.4 \%)$ & $x^{2}=188.93$ & $<0.0001$ \\
\hline Chest pain & $975(7.6 \%)$ & $1137(4.4 \%)$ & $x^{2}=164.51$ & $<0.0001$ \\
\hline Urogenital/pelvic/menstrual pain & $280(2.2 \%)$ & $442(1.7 \%)$ & $x^{2}=9.69$ & 0.0018 \\
\hline Fractures/contusions/sprains/strains & $1392(10.8 \%)$ & $1968(7.6 \%)$ & $x^{2}=107.50$ & $<0.0001$ \\
\hline Other painful conditions ${ }^{a}$ & $1117(8.7 \%)$ & $1884(7.3 \%)$ & $x^{2}=21.71$ & $<0.0001$ \\
\hline Chronic opioid use $^{b}$ & $845(6.5 \%)$ & $1299(5.0 \%)$ & $x^{2}=37.29$ & $<0.0001$ \\
\hline
\end{tabular}

Includes sickle cell disease, Complex Regional Pain Syndrome, systemic lupus erythematosus, acquired deformities (excluding spinal disorders), spinal cord injury, Lyme disease, Neuropathic pain

${ }^{\mathrm{b}}$ Chronic use defined by $70+$ days supply in a 90 day period, receiving $6+$ dispenses in a year

CNCP-related diagnoses compared to matched controls; by contrast, individuals with schizophrenia or schizoaffective disorder were significantly less likely to receive CNCP-related diagnoses compared to matched controls. These findings confirm and extend those from previous studies [17, 27, 28] and suggest that the pattern of CNCP-related diagnoses may be different for individuals with MDD or BD than for individuals with schizophrenia or schizoaffective disorder. This finding is not surprising given that symptoms of MDD and BD overlap more with each other than with symptoms of schizophrenia and schizoaffective disorder [19].

Compared to the general population, individuals with schizophrenia have increased risk of experiencing multiple physical comorbidities warranting pain control [29-32] and thus it seems counterintuitive that they 
Table 4 Odds of Receiving a Chronic Pain Diagnosis and Chronic Opioid Prescriptions among Individuals with Versus without Mental Illness

\begin{tabular}{lll}
\hline Mental IIIness Diagnosis & Chronic Pain Diagnosis $^{\mathrm{a}}$ & Opioid Prescription $^{b}$ \\
& Adjusted OR (Cl) & Adjusted OR (Cl) \\
\hline Major Depressive Disorder & $1.90(1.85-1.95)^{*}$ & $2.59(2.44-2.75)^{*}$ \\
Bipolar Disorder & $1.71(1.66-1.77)^{*}$ & $2.12(1.97-2.28)^{*}$ \\
Schizophrenia & $0.86(0.82-0.90)^{*}$ & $1.00(0.91-1.11)$ \\
\hline
\end{tabular}

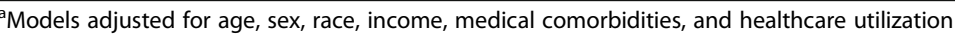

${ }^{\mathrm{b}}$ Models adjusted for age, sex, race, income, medical comorbidities, healthcare utilization and chronic pain diagnosis ${ }^{*} p<0.001$

were less likely to receive $\mathrm{CNCP}$ diagnoses than controls in the present study. There are several possible explanations for the lower prevalence of CNCP diagnoses among individuals with schizophrenia. First, there is some evidence that individuals with schizophrenia have reduced sensitivity to pain compared to individuals without psychiatric illness [33-36]. Further, antipsychotics have been shown to have analgesic qualities [37]; therefore, this decreased likelihood of receiving a pain diagnosis could reflect lower levels of pain. However, results from a recent meta-analysis indicate that antipsychoticfree patients with schizophrenia also had elevated pain thresholds compared to controls [36]. An alternative explanation may be that individuals with schizophrenia are less likely to express pain rather than actually experiencing less pain, either because they are unable to adequately describe the physical symptoms due to social communication impairments [38] or they withhold this information because of concerns about how they will be treated by healthcare providers. For example, Kuritzky and colleagues reported that a large percentage of people ( 40\%) with schizophrenia who had pain-related complaints indicated that they never reported these complaints in order to avoid being perceived a burden to providers and/or to avoid hospitalization [17, 39]. However, another study with Veterans Health Administration patients found that patients with schizophrenia were twice more likely to report chronic pain in comparison to those without schizophrenia [19]. Therefore, given these conflicting findings, authors of recent systematic review suggest that it is likely more appropriate to state that pain experience in schizophrenia is disturbed or distorted rather than decreased or absent [38].

Behavioral health clinicians may be less likely to assign pain-related diagnoses for individuals with schizophrenia because many have limited training in physical symptom management [40] and are more focused on treating psychiatric than medical concerns [41-43]; primary care clinicians may be less likely to assign pain-related diagnoses because their short consultation times make it difficult to both assess mental symptoms and conduct physical assessments. Additionally, less experienced providers may be uncomfortable with serious mental illness and may avoid intensifying their interaction with a patient by asking probing questions about physical symptoms and performing a physical exam [40]. Indeed, there is ample evidence that individuals with schizophrenia are less likely than their peers without any psychiatric illnesses to receive medical procedures and treatments for a range of conditions including cancer screening and treatment [44], use of antihypertensive and lipid-lowering drugs [45] and appropriate diabetes care (including $\mathrm{A} 1 \mathrm{C}$ and cholesterol testing, eye and feet exams, etc.) [46, 47]. Future studies are needed to better understand providers' decision-making with respect to diagnosing and treating pain among patients with schizophrenia.

This lack of expression and/or disclosure of painrelated complaints by patients or under-diagnosis by providers may lead to the under-detection and undertreatment of CNCP among individuals with schizophrenia. This is problematic given that CNCP among individuals with mental illness is associated with worsening of psychiatric symptoms, impaired recovery/poor therapeutic response $[19,48]$, greater functional incapacitation [49, 50], lower quality of life [51, 52] and increased risk of suicide [53, 54]. Therefore, it is essential to systematically assess and monitor CNCP-related conditions among individuals with schizophrenia. Psychiatrists may be particularly well-suited to oversee pain management in this population and thus need adequate education and training to equip them to do so [55].

The present study also found that individuals with MDD and BD diagnoses were over two times more likely to receive chronic opioid medication prescriptions compared to matched controls. This finding is consistent with prior literature which has similarly reported that opioids are more commonly prescribed (and prescribed at higher doses) in these populations compared to those without these mental health conditions, even after controlling for a wide array of other demographic and clinical risk factors $[10,13,15,16]$. One explanation for this is that these individuals may present with greater pain severity [56], thereby increasing the likelihood that clinicians will prescribe an opioid and at a higher dose [57]. However, the relationship between depressive symptoms 
and opioid use is complex and likely bidirectional in nature, as prior research indicates that chronic opioid use can increase the risk of new-onset depression [58] as well as depression recurrence [59]. Regardless of the nature of the causal relationship, there is evidence that mental illness is associated with diminished opioid analgesia [60] and, more importantly, mental illness is a known risk factor for a range of adverse opioid-related outcomes including opioid use disorder [61-65]. Therefore, individuals most at risk for developing opioidrelated problems are also more likely to be prescribed opioids [11]. Healthcare providers should be especially conservative in prescribing opioids for individuals with mental illness - or avoid opioid therapy altogether for this population, consistent with the current Canadian Medical Association recommendation [66] - and instead, favor non-pharmacological alternatives [16] such as behavioral/psychosocial approaches.

The present study has several limitations. First, opioid prescription data is based on dispensings, and thus may not accurately represent patients' actual medication use. Second, we categorized patients who had more than 1 mental health diagnosis hierarchically; therefore, a patient with schizophrenia could also have had depression but he/she would not have been included in the analyses on individuals with depression. Thus our findings should be interpreted accordingly - e.g., depression is associated with an increased odds of a pain diagnosis and receipt of opioid prescriptions when not comorbid with schizophrenia. However, consistent with diagnostic criteria [67], we applied a hierarchy with diagnosis of schizophrenia superseding a diagnosis of mood disorder and bipolar disorder superseding a diagnosis of unipolar depression. Third, study results were derived from a sample of members of integrated payer-provider systems. There is some evidence to suggest that individuals who are more economically and socially disadvantaged may be more severely ill [68]. Therefore, our largely insured sample may underrepresent the most impaired patients. Thus, caution is urged in generalizing the findings to uninsured populations. This study's strengths include a large, geographically and racially/ethnically diverse study population, the comparison of 3 populations with serious mental illness to matched controls, and the inclusion of important statistical confounders such as healthcare utilization in multivariate models.

\section{Conclusions}

The presence of pain significantly impacts individuals' engagement in and adherence to their mental health treatment and is an important moderator of treatmentrelated outcomes with respect to both pharmacotherapy and psychotherapy $[69,70]$. Therefore, the systematic assessment and treatment of pain among individuals with mental illness is critical to short- and long-term improvements in quality of life. Given the lack of evidence about efficacy of long-term opioid treatment for $\mathrm{CNCP}$ and risks of drug interactions and/or use disorders, specifically among individuals with serious mental illness, non-pharmacological (e.g., behavioral/psychosocial) treatments are needed for this population. Unfortunately, barriers to accessing these types of interventions exist, such as limited patient and clinician awareness, stigma, limited capacity and reimbursement issues [69]. Consequently, there have been recent calls for engaging mental health clinicians in pain treatment for this population, as they may be particularly well-suited to assess pain symptoms, incorporate pain into treatment plans and encourage self-management activities and participation in behavioral/psychosocial treatments for pain [69]. Future research is needed to evaluate the effectiveness of involving mental health clinicians in pain management.

\section{Abbreviations}

BD: Bipolar disorder; CNCP: Chronic non-cancer pain; MDD: Major depressive disorder; MHRN: Mental Health Research Network

\section{Acknowledgements}

The authors would like to thank all members of the Health Care Systems and Mental Health Research Networks, whose contributions to building the Virtual Data Warehouse and to the integrity of the data have made this study possible.

\section{Authors' contributions}

AOS, CS and MS had full access to all of the data and take responsibility for the integrity of the data and accuracy of the data analysis. AOS, CS and MS made substantial contributions to the conception of the work, the data analysis and interpretation of the results and drafted and revised the work. SMS, BJY, BA, LMM, SW, IH, BW, SAS, CC, RH, JZ, LC, JS, RR and GS made substantial contributions to the conception of the work, the interpretation of the results and contributed substantively to the revision of the work. All authors read and approved the final version of the manuscript.

\section{Funding}

This project was supported by Award Number U19MH092201 from the National Institute of Mental Health. The content is solely the responsibility of the authors and does not necessarily represent the official views of the National Institute of Mental Health or the National Institutes of Health.

\section{Availability of data and materials}

All SAS code is provided on the MHRN GitHub site: see https://github.com/ MHResearchNetwork/MHRN-Central/blob/master/WP_MHRN_SMI_ painOpioids.zip

Individual-level data cannot not be shared because individual patients could be re-identified; aggregated and de-identified data can be requested by contacting the first author, Dr. Ashli Owen-Smith (aowensmith@gsu.edu).

\section{Ethics approval and consent to participate}

Institutional Review Boards at each of the following sites approved the study protocol for this project: Kaiser Permanente Georgia, Kaiser Permanente Washington, Kaiser Permanente Northwest, Kaiser Permanente Hawaii, Kaiser Permanente Northern California, Kaiser Permanente Southern California, Henry Ford Health System, Essentia Institute of Rural Health, Baylor Scott and White Healthcare and Health Partners Institute.

\section{Consent for publication}

Not applicable.

Competing interests

The authors declare that they have no competing interests. 


\section{Author details}

'Health Policy and Behavioral Sciences, School of Public Health, Georgia State University, Urban Life Building, 140 Decatur Street, Suite 434, Atlanta, GA 30303, USA. ${ }^{2}$ Center for Research and Evaluation, Kaiser Permanente Georgia, Atlanta, USA. ${ }^{3}$ Health Research Institute, Kaiser Permanente Washington, Seattle, USA. ${ }^{4}$ Center for Health Research, Kaiser Permanente Northwest, Portland, USA. ${ }^{5}$ Center for Health Policy and Health Services Research, Henry Ford Health System, Detroit, USA. ${ }^{6}$ Depart Behavioral Health Services, Henry Ford Health System, Detroit, USA. ${ }^{7}$ Essentia Institute of Rural Health, Duluth, USA. ${ }^{8}$ Center for Health Research, Kaiser Permanente Hawaii, Honolulu, USA. ${ }^{9}$ Division of Research, Kaiser Permanente Northern California, Oakland, USA. ${ }^{10}$ Department of Research and Evaluation, Kaiser Permanente Southern California, Pasadena, USA. ${ }^{11}$ School of Public Health \& Health Sciences, University of Massachusetts Amherst, Amherst, USA. ${ }^{12}$ A Central Western Massachusetts Healthcare, Leeds, MA, USA. ${ }^{13}$ Department of Family and Community Medicine, Saint Louis University School of Medicine, Saint Louis, USA. ${ }^{14}$ Health Partners Institute, Minneapolis, USA.

Received: 27 June 2019 Accepted: 22 January 2020

Published online: 31 January 2020

\section{References}

1. Nahin RL. Estimates of pain prevalence and severity in adults: United States, 2012. J Pain. 2015;16(8):769-80.

2. National Center for Health Statistics. Health, United States, 2006 With Chartbook on Trends in the Health of Americans2006. Available from: https://www.cdc.gov/nchs/data/hus/hus06.pdf.

3. Caudill-Slosberg MA, Schwartz LM, Woloshin S. Office visits and analgesic prescriptions for musculoskeletal pain in US: 1980 vs. 2000 Pain. 2004;109(3):514-9.

4. Edlund MJ, Martin BC, Devries A, Fan MY, Braden JB, Sullivan MD. Trends in use of opioids for chronic noncancer pain among individuals with mental health and substance use disorders: the TROUP study. Clin J Pain. 2009;26(1):1-8

5. Gilson A, Ryan KM, Joranson DE, Dahl JL. A reassessment of trends in the medical use and abuse of opioid analgesics and implications for diversion control: 1997-2002. J Pain Symptom Manag. 2004;28(2):176-88.

6. Ballantyne JC, Shin NS. Efficacy of opioids for chronic pain: a review of the evidence. Clin J Pain. 2008;24(6):469-78.

7. Chaparro LE, Furlan AD, Deshpande A, Mailis-Gagnon A, Atlas S, Turk DC Opioids compared to placebo or other treatments for chronic low-back pain. Cochrane Database Syst Rev. 2013;8:CD004959.

8. Rudd RA, Seth P, David F, Scholl L. Increases in drug and opioid-involved overdose deaths - United States, 2010-2015. MMWR Morb Mortal Wkly Rep. 2016;65(5051):1445-52.

9. Centers for Disease Control and Prevention. Understanding the epidemic: drug overdose deaths in the United States continue to increase in 20152011 [Available from: https://www.cdc.gov/ drugoverdose/epidemic/index.html.

10. Braden JB, Sullivan MD, Ray GT, Saunders K, Merrill J, Silverberg MJ, et al. Trends in long-term opioid therapy for noncancer pain among persons with a history of depression. Gen Hosp Psychiatry. 2009;31(6):564-70.

11. Edlund MJ, Austen MA, Sullivan MD, Martin BC, Williams JS, Fortney JC, et al. Patterns of opioid use for chronic noncancer pain in the veterans health administration from 2009 to 2011. Pain. 2014;155(11):2337-43.

12. Merrill JO, Von Korff M, Banta-Green CJ, Sullivan MD, Saunders KW, Campbell Cl, et al. Prescribed opioid difficulties, depression and opioid dose among chronic opioid therapy patients. Gen Hosp Psychiatry 2012;34(6):581-7.

13. Spivak S, Cullen B, Eaton W, Nugent K, Spivak A, Fenton A, et al. Prescription opioid use among individuals with serious mental illness. Psychiatry Res. 2018;267:85-7

14. Sullivan MD, Edlund MJ, Zhang L, Unutzer J, Wells KB. Association between mental health disorders, problem drug use, and regular prescription opioid use. Arch Intern Med. 2006;166(19):2087-93.

15. Mathew N, Rosenheck R. Prescription opioid use among seriously mentally ill veterans nationally in the veterans health administration. Community Ment Health J. 2016:52(2):165-73.

16. Davis $M A$, Lin LA, Liu $H$, Sites BD. Prescription opioid use among adults with mental health disorders in the United States. J Am Board Fam Med. 2017;30(4):407-17.
17. Engels G, Francke AL, van Meijel B, Douma JG, de Kam H, Wesselink W, et al. Clinical pain in schizophrenia: a systematic review. J Pain. 2014;15(5):457-67.

18. Failde I, Dueñas M, Agüera-Ortíz L, Cervilla JA, Gonzalez-Pinto A, Mico JA. Factors associated with chronic pain in patients with bipolar depression: a cross-sectional study. BMC Psychiatry. 2013;13:112.

19. Birgenheir DG, Ilgen MA, Bohnert ASB, Abraham KM, Bowersox NW, Austin $K$, et al. Pain conditions among veterans with schizophrenia or bipolar disorder. Gen Hosp Psychiatry. 2013;35(5):480-4.

20. Ross TR, Ng D, Brown JS, Pardee R, Hornbrook MC, Hart G, et al. The HMO Research Network Virtual Data Warehouse: A Public Data Model to Support Collaboration. EGEMS (Wash DC). 2014:2(1):1049.

21. Copeland LA, Sako EY, Zeber JE, Pugh MJ, Wang C-P, MacCarthy AA, et al. Mortality after cardiac or vascular operations by preexisting serious mental illness status in the veterans health administration. Gen Hosp Psychiatry. 2014:36(5):502-8.

22. Copeland LA, Zeber JE, Sako EY, Mortensen EM, Pugh MJ, Wang C-P, et al. Serious mental illnesses associated with receipt of surgery in retrospective analysis of patients in the Veterans Health Administration. BMC Surgery. 2015;15:74.

23. Turner JA, Saunders K, Shortreed SM, Rapp SE, Thielke S, LeResche L, et al. Chronic opioid therapy risk reduction initiative: impact on urine drug testing rates and results. J Gen Intern Med. 2014;29(2):305-11.

24. Von Korff M, Dublin S, Walker RL, Parchman M, Shortreed SM, Hansen RN, et al. The impact of opioid risk reduction initiatives on high-dose opioid prescribing for patients on chronic opioid therapy. J Pain. 2016;17(1):101-10.

25. Owen-Smith A, Stewart C, Green C, Ahmedani BK, Waitzfelder BE, Rossom R, et al. Adherence to common cardiovascular medications in patients with schizophrenia vs. patients without psychiatric illness. Gen Hosp Psychiatry. 2016:38:9-14

26. Charlson ME, Pompei $\mathrm{P}$, Ales KL, Mackenzie CR. A new method of classifying prognostic comorbidity in longitudinal studies: development and validation. J Chronic Dis. 1987:40(5):373-83.

27. Stubbs B, Eggermont L, Mitchell AJ, De Hert M, Correll CU, Soundy A, et al. The prevalence of pain in bipolar disorder: a systematic review and largescale meta-analysis. Acta Psychiatr Scand. 2015;131(2):75-88.

28. Nicholl BI, Mackay D, Cullen B, Martin DJ, Ul-Haq Z, Mair FS, et al. Chronic multisite pain in major depression and bipolar disorder: cross-sectional study of 149,611 participants in UK Biobank. BMC Psychiatry. 2014;14:350.

29. Fan Z, Wu Y, Shen J, Ji T, Zhan R. Schizophrenia and the risk of cardiovascular diseases: a meta-analysis of thirteen cohort studies. J Psychiatr Res. 2013;47(11):1549-56.

30. Li M, Fan YL, Tang ZY, Cheng XS. Schizophrenia and risk of stroke: a metaanalysis of cohort studies. Int J Cardiol. 2014;173(3):588-90.

31. Stubbs B, Vancampfort D, De Hert M, Mitchell AJ. The prevalence and predictors of type two diabetes mellitus in people with schizophrenia: a systematic review and comparative meta-analysis. Acta Psychiatr Scand. 2015:132(2):144-57.

32. Tegethoff M, Belardi A, Stalujanis E, Meinlschmidt G. Comorbidity of mental disorders and chronic pain: chronology of onset in adolescents of a National Representative Cohort. J Pain. 2015;16(10):1054-64.

33. Atik L, Konuk N, Akay O, Ozturk D, Erdogan A. Pain perception in patients with bipolar disorder and schizophrenia. Acta Neuropsychiatr. 2007:19(5):284-90.

34. Blumensohn R, Ringler D, Eli I. Pain perception in patients with schizophrenia. J Nerv Ment Dis. 2002;190(7):481-3.

35. de la Fuente-Sandoval C, Favila R, Gomez-Martin D, Pellicer F, Graff-Guerrero A. Functional magnetic resonance imaging response to experimental pain in drug-free patients with schizophrenia. Psychiatry Res. 2010;183(2):99-104.

36. Stubbs B, Thompson T, Acaster S, Vancampfort D, Gaughran F, Correll CU. Decreased pain sensitivity among people with schizophrenia: a metaanalysis of experimental pain induction studies. Pain. 2015;156(11):2121-31.

37. Seidel $S$, Aigner $M$, Ossege M, Pernicka E, Wildner B, Sycha T. Antipsychotics for acute and chronic pain in adults. J Pain Symptom Manag. 2010;39(4):768-78.

38. Bonnot O, Anderson GM, Cohen D, Willer JC, Tordjman S. Are patients with schizophrenia insensitive to pain? A reconsideration of the question. Clin J Pain. 2009;25(3):244-52.

39. Kuritzky A, Mazeh D, Levi A. Headache in schizophrenic patients: a controlled study. Cephalalgia. 1999;19(8):725-7.

40. Phelan M, Stradins L, Morrison S. Physical health of people with severe mental illness. BMJ. 2001;322(7284):443-4. 
41. Dickerson FB, Brown CH, Daumit GL, Fang L, Goldberg RW, Wohlheiter K, et al. Health status of individuals with serious mental illness. Schizophr Bull. 2006;32(3):584-9.

42. Fleischhacker WW, Cetkovich-Bakmas M, De Hert M, Hennekens CH, Lambert M, Leucht S, et al. Comorbid somatic illnesses in patients with severe mental disorders: clinical, policy, and research challenges. J Clin Psychiatry. 2008;69(4):514-9.

43. Heald A. Physical health in schizophrenia: a challenge for antipsychotic therapy. Eur Psychiatry. 2010;25(Suppl 2):S6-11.

44. Irwin KE, Henderson DC, Knight HP, Pirl WF. Cancer care for individuals with schizophrenia. Cancer. 2014;120(3):323-34.

45. Ayerbe L, Forgnone I, Foguet-Boreu Q, Gonzalez E, Addo J, Ayis S. Disparities in the management of cardiovascular risk factors in patients with psychiatric disorders: a systematic review and meta-analysis. Psychol Med. 2018;48(16):2693-701.

46. Desai MM, Rosenheck RA, Druss BG, Perlin JB. Mental disorders and quality of diabetes care in the veterans health administration. Am J Psychiatry. 2002;159(9):1584-90.

47. Frayne $\mathrm{SM}$, Halanych $\mathrm{JH}$, Miller DR, Wang F, Lin H, Pogach L, et al. Disparities in diabetes care: impact of mental illness. Arch Intern Med. 2005; 165(22):2631-8.

48. Kroenke K, Shen J, Oxman TE, Williams JW Jr, Dietrich AJ. Impact of pain on the outcomes of depression treatment: results from the RESPECT trial. Pain. 2008;134(1-2):209-15.

49. Mclntyre RS, Konarski JZ, Wilkins K, Bouffard B, Soczynska JK, Kennedy $\mathrm{SH}$. The prevalence and impact of migraine headache in bipolar disorder: results from the Canadian community health survey. Headache. 2006:46(6):973-82.

50. Hirschfeld RM, Calabrese JR, Weissman MM, Reed M, Davies MA, Frye MA, et al. Screening for bipolar disorder in the community. J Clin Psychiatry. 2003;64(1):53-9.

51. Miller CJ, Abraham KM, Bajor LA, Lai Z, Kim HM, Nord KM, et al. Quality of life among patients with bipolar disorder in primary care versus community mental health settings. J Affect Disord. 2013;146(1):100-5.

52. JGd A, Braga PE, Lotufo Neto F, CAdM P. Chronic pain and quality of life in schizophrenic patients. Revista Brasileira De Psiquiatria (Sao Paulo, Brazil: 1999). 2013;35(1):13-20.

53. Ilgen MA, Zivin K, McCammon RJ, Valenstein M. Pain and suicidal thoughts, plans and attempts in the United States. Gen Hosp Psychiatry. 2008;30(6):521-7.

54. Ratcliffe GE, Enns MW, Belik SL, Sareen J. Chronic pain conditions and suicidal ideation and suicide attempts: an epidemiologic perspective. Clin J Pain. 2008;24(3):204-10.

55. Stubbs B, Mitchell AJ, De Hert M, Correll CU, Soundy A, Stroobants M, et al. The prevalence and moderators of clinical pain in people with schizophrenia: a systematic review and large scale meta-analysis. Schizophr Res. 2014;160(1-3):1-8

56. Borsbo B, Peolsson M, Gerdle B. The complex interplay between pain intensity, depression, anxiety and catastrophising with respect to quality of life and disability. Disabil Rehabil. 2009;31(19):1605-13.

57. Goesling J, Henry MJ, Moser SE, Rastogi M, Hassett AL, Clauw DJ, et al. Symptoms of depression are associated with opioid use regardless of pain severity and physical functioning among treatment-seeking patients with chronic pain. J Pain. 2015;16(9):844-51.

58. Scherrer JF, Svrakic DM, Freedland KE, Chrusciel T, Balasubramanian S, Bucholz KK, et al. Prescription opioid analgesics increase the risk of depression. J Gen Intern Med. 2014;29(3):491-9.

59. Scherrer JF, Salas J, Copeland LA, Stock EM, Schneider FD, Sullivan M, et al. Increased risk of depression recurrence after initiation of prescription opioids in noncancer pain patients. J Pain. 2016;17(4):473-82.

60. Wasan AD, Davar $G$, Jamison R. The association between negative affect and opioid analgesia in patients with discogenic low back pain. Pain. 2005; 117(3):450-61.

61. Schieffer BM, Pham Q, Labus J, Baria A, Van Vort W, Davis P, et al. Pain medication beliefs and medication misuse in chronic pain. J Pain. 2005;6(9):620-9.

62. Wasan AD, Butler SF, Budman SH, Benoit C, Fernandez K, Jamison RN. Psychiatric history and psychologic adjustment as risk factors for aberrant drug-related behavior among patients with chronic pain. Clin J Pain. 2007; 23(4):307-15.

63. Edlund MJ, Martin BC, Fan MY, Devries A, Braden JB, Sullivan MD. Risks for opioid abuse and dependence among recipients of chronic opioid therapy: results from the TROUP study. Drug Alcohol Depend. 2010;112(1-2):90-8.
64. Park J, Lavin R. Risk factors associated with opioid medication misuse in community-dwelling older adults with chronic pain. Clin J Pain. 2010; 26(8):647-55.

65. Park TW, Lin LA, Hosanagar A, Kogowski A, Paige K, Bohnert AS. Understanding risk factors for opioid overdose in clinical populations to inform treatment and policy. J Addict Med. 2016;10(6):369-81.

66. Busse JW, Craigie S, Juurlink DN, Buckley DN, Wang L, Couban RJ, et al. Guideline for opioid therapy and chronic noncancer pain. CMAJ. 2017; 189(18):E659-E66.

67. American Psychiatric Association. Diagnostic and statistical manual of mental disorders. 2013 [5th Edition.:[Available from: https://doi.org/10.1176/ appi.books.9780890425596.

68. McAlpine DD, Mechanic D. Utilization of specialty mental health care among persons with severe mental illness: the roles of demographics, need, insurance, and risk. Health Serv Res. 2000:35(1 Pt 2):277-92.

69. Edmond SN, Heapy AA, Kerns RD. Engaging Mental Health Professionals in Addressing Pain. JAMA Psychiatry. 2019;76:565.

70. Martucci KT, Ng P, Mackey S. Neuroimaging chronic pain: what have we learned and where are we going? Future Neurol. 2014;9(6):615-26.

\section{Publisher's Note}

Springer Nature remains neutral with regard to jurisdictional claims in published maps and institutional affiliations.
Ready to submit your research? Choose BMC and benefit from:

- fast, convenient online submission

- thorough peer review by experienced researchers in your field

- rapid publication on acceptance

- support for research data, including large and complex data types

- gold Open Access which fosters wider collaboration and increased citations

- maximum visibility for your research: over $100 \mathrm{M}$ website views per year

At $\mathrm{BMC}$, research is always in progress.

Learn more biomedcentral.com/submissions 